\title{
Infodemia, el lado obscuro de la comunicación digital
}

\section{Infodemia, the dark side of digital communication}

DOI: $10.46932 / \mathrm{sfjdv2n4-038}$

Received in: May 1st, 2021

Accepted in: Jun 30th, 2021

\author{
Sandra Flores Guevara \\ Doctora en Ciencias Sociales por la Universidad Autónoma Metropolitana, Unidad Xochimilco \\ Institucción actual: Universidad Autónoma del Estado de Hidalgo \\ Dirección: Carr. a Pachuca 2681, Colosio, 42102 Pachuca de Soto, Hgo. \\ E-mail: sandra_flores@uaeh.edu.mx
}

\begin{abstract}
Fannia María Cadena Montes
Maestra en Estudios de Población por la Universidad Autónoma del Estado de Hidalgo

Institución actual: Universidad Autónoma del Estado de Hidalgo

Dirección: Carr. a Pachuca 2681, Colosio, 42102 Pachuca de Soto, Hgo.

E-mail: fanniamariacadena@gmail.com
\end{abstract}

\author{
Ramiro Cadena Uribe \\ Maestro en Estudios de Población por la Universidad Autónoma del Estado de Hidalgo \\ Institución actual: Universidad Autónoma del Estado de Hidalgo \\ Dirección: Pachuca-Tulancingo Km. 4.5, Carboneras, 42184 Pachuca de Soto, Hgo. \\ E-mail: ramiro_cadena@uaeh.edu.mx
}

\section{RESUMEN}

El espacio virtual donde se han logrado abrir camino medios de comunicación digitales alternativos, y donde se informa la mayoría de los mexicanos, hoy se encuentra contaminado por el virus de la desinformación y las fake news. La llegada del virus Covid-19 ha sido terreno fértil para la propagación de la infodemia, y una herramienta de la oposición para golpear al gobierno del presidente de México, Andrés Manuel López Obrador.

Ante esta epidemia de desinformación, el propósito de este trabajo es visibilizar las consecuencias que tiene la propagación de información falsa en torno al Covid-19, analizando para ello el uso político que se le da a los rumores y fake news que se difunden tanto en redes sociales digitales como en medios de comunicación.

Entre los principales halazgos de este estudio de corte cualitativo, se pudieron distinguir algunos medios de comunicación que propician y otros que combaten a la infodemia. Además se observó que la epidemia de información falsa tiene graves consecuencias en la sociedad, con implicaciones que van desde afectaciones a la salud pública, hasta la desacreditación de movimientos sociales genuinos como el femeninismo, o de gobiernos legítimos.

Palabras clave: Infodemia, medios de comunicación, redes sociales digitales

\footnotetext{
ABSTRACT

The virtual space where alternative digital media have made their way, and where the majority of Mexicans are informed, is now contaminated by the virus of disinformation and fake news. The arrival of the Covid-19 virus has been fertile ground for the spread of infodemia, and a tool of the opposition to hit the government of the president of Mexico, Andrés Manuel López Obrador.
} 
Given this epidemic of disinformation, the purpose of this paper is to make visible the consequences of the spread of false information about Covid-19, analyzing the political use given to rumors and fake news that are spread both in digital social networks and in the media.

Among the main findings of this qualitative study, it was possible to distinguish some media that favor and others that fight infodemia. In addition, it was observed that the epidemic of false information has serious consequences in society, with implications ranging from public health effects to the discrediting of genuine social movements such as feminism, or of legitimate governments.

Keywords: Infodemia, media, digital social networks

\section{INTRODUCCIÓN}

Un nuevo virus recorre las redes sociales digitales infectándolas más rápido y más nocivamente, causando desinformación, incertidumbre, miedo y alarma. El presidente de México, Andrés Manuel López Obrador, atribuyó su victoria en las pasadas elecciones presidenciales, a "las benditas redes sociales", que han influido en una mayor politización de la población.

Lo anterior ratifica que los medios de comunicación digitales o alternativos ya han desplazado a los medios tradicionales como la prensa o los noticieros de radio y televisión; sin embargo, el mundo virtual que se había caracterizado por su credibilidad y por la saturación de noticias hoy está infectándose con este virus propagado principalmente por la derecha mexicana, hoy oposición al actual gobierno.

El virus ha mutado en distintas formas, desde las noticias falsas o fake news, hasta los rumores esparcidos en redes sociales digitales, ambos potencializados mediante un ejército de bots, creando así una epidemia de desinformación, es decir, una infodemia. La Organización Mundial de la Salud, utilizó el término infodemia para referirse a la sobreabundancia de información falsa, maliciosa o medias verdades sobre la pandemia y su rápida propagación a través de las personas y de los usuarios de redes sociales virtuales como Twitter, Facebook, WhatsApp, Instagram y YouTube.

Ante ese scenario, el objetivo de esta investigación es analizar el uso político que se le da a la información, las noticias falsas y rumores, que constituyen los principales elementos de la infodemia, a través de diferentes procesos sociales de coyuntura nacional, mediante una metodología cualitativa basada en el análisis de contenidos de medios de comunicación y redes sociales virtuales.

\section{DESARROLLO}

\subsection{ANTECEDENTES}

La pandemia ocasioanada por el virus COVID-19 y las elecciones de 2021 han agudizado la batalla en los medios de comunicación y las plataformas digitales en México, polarizando así la opinión pública entre dos principales sectores: quienes defienden el discurso neoliberal para conservar los viejos 
privilegios, y quienes comprenden las grandes desigualdades sociales y dan voz a los grupos históricamente relegados.

Los sectores involucrados en dicha batalla mediática son los medios tradicionales de comunicación, la oposición al actual gobierno mexicano, el propio gobierno de la Cuarta Transformación, y los ciudadanos, convertidos in internaturas que navegan entre las diferentes opiniones y toman una postura política.

La alta circulación de información, y mercantilización de la misma, ha creado un terreno propicio para la desinformación, las fake news, y lo que hoy se conoce como infodemia, que la Organización Mundial de la Salud ha definido como la sobreabundancia de información falsa, maliciosa o medias verdades sobre la pandemia.

La infodemia ha crecido de forma exponencial si se toma como referencia que en México, 86 por ciento utiliza medios de comunicación en línea o digitales para informarse, y 70 por ciento lo hace en redes sociales; quienes se enteran de las noticias por medio de la televisión representan el 48 por ciento, y quienes lo hacen en medios impresos, representan el 26 por ciento ${ }^{1}$.

Es en los medios digitales donde se informa la mayoría de la población, y es en ese universo en el que se ha desatado la ola de desifotmación, noticias falsas, y la infodemia, las cuales conllevan intereses de los diferentes grupos políticos.

Hay que destacar que en las redes sociales donde se informa cerca del 70 por ciento de la población, 80 por ciento lo hace a través de Facebook, y 78 por ciento mediante Youtube. Según el Edelman Trust Barometer (2018), los usuarios estaban preocupados por el uso de fake news como armas.

Los medios de comunicación masiva tradicionales, han migrado al espacio virtual, y en él han surgido nuevos medios de comunicación masiva que son nativos digitales, entre los primeros se puede citar a Animal Político y el portal SinEmbargo.mx; de esa forma, medios tradicionales con los digitales se apropian del mundo digital a través de sus propias páginas web y de sus extensiones en las distintas redes sociales virtuales.

Ese contexto, en el que se pluralizan los medios de comunicación en el espacio virtual, coincide con el cambio de régimen político en México. Justamente, el presidente Andrés Manuel López Obrador atribuyó su triunfo en las urnas en 2018, no solo a los años de lucha y persistencia en el viciado sistema político-electoral mexicano, sino a "las benditas redes sociales".

Comenzó entonces un proceso de democratización de los medios de comunicación, al recibir ahora el 50 por ciento del subsidio que el gobierno federal les otorgaba. Esto implicó una mayor libertad de expresión de los medios de comunicación, así como una mayor independencia en sus líneas editoriales.

\footnotetext{
${ }^{1}$ Digital News Report (2020). Reuters Institute de la Universidad de Oxford.
} 
“Les quitaron el bozal y la correa. Dejaron de darles línea, no saben qué hacer, no saben para qué sirve la libertad de expresión de la que ahora gozan porque siempre han escrito o hablado ante el micrófono o la cámara por consigna, vendiéndose al mejor postor", así lo escribió el periodista y productor de televisión Epigmenio Ibarra, en una de sus columnas que tituló "Comentocracia", en referencia a las grandes figuras de los medios de comunicación tradicionales.

La publicidad oficial representaba -y lo sigue haciendo-, un gran incentivo para los medios de comunicación, que explica a su vez la relación de estos con el poder en los sexenios anteriores y la poca libertad de prensa que existía.

Basta con analizar cómo la llamada "comentocracia" de la que habla Epigmenio Ibarra, ha acaparado gran parte de los principales medios de comunicación. Por poner algunos ejemplos, Joaquín López Dóriga ha acaparado mos mmedios de comunicación como El Universal, Milenio y Grupo Fórmula. Por su parte, Carlos Loret de Mola ha estado presente en Radio Fórmula, W Radio, El Universal, The Washington Post, y más recientemente, LatinUS. El periodista Ciro Gómez Leyva ha pasado por Milenio TV, Radio Fórmula, e Imagen TV.

Se podría decir que Carmen Aristegui es uno de los pocos espacios divergentes, es decir que no ha estado en ninguno de estos grandes medios de comunicación antes citados. Así se puede observar que más del 80 por ciento de los medios de comunicación están monopolizados por esta élite de periodistas o informadores.

Existe hasta la fecha este esquema de concentración que implica un empobrecimiento de la pluralidad de voces e ideas u opiniones. Con algunos matices, pero todos estos periodistas antes mencionados mantienen una misma visión, de forma que este grupo o comentócratas monopolizan la opinión. Estos opinólogos han construido la forma en que los ciudadanos ven al país, su forma de percibir la política y su forma de vivir su realidad.

Sin embargo, las nuevas tecnologías han ampliado la discusión pública con la creación de nuevos medios de comunicación digitales y nuevas plumas que dinamitan las redes sociales digitales y encienden los debates políticos.

La comunicación ya no es unidireccional, del medio de comunicación hacia los lectores, sino que estos generan también una opinión que muchos usuarios más pueden ver, compartir, e incluso responder. Se crea entonces una comunicación multidireccional. El paradigma de "el medio es el mensaje", cambió al de "la audiencia es el mensaje".

Surgen en las redes sociales virtuales encendidos debates que han polarizado y radicalizado las posturas de los llamados líderes de opinión, así como de los cibernautas, de forma que se popularizaron términos como "chairo" y fifí". Una de las estrategias utilizada para salir avante en medio de esta 
ebullición de información y opiniones, ha sido la "guerra sucia", donde a través de bots o cuentas automatizadas de usuarios en redes sociales como Twitter, se han inflado artificialmente tendencias, o bien apoyado o apaleado a determinados personajes de la vida pública del país.

Es de resaltar aquí cómo las nuevas tecnologías, mediante aplicaciones accesibles a cualquier usuario de internet, se han convertido en una herramienta útil para la creación de noticias falsas o fake news, ya que es posible alterar imágenes o fotografías, o bien descontextualizarlas para generar una noticia falsa.

Existen dos narrativas principales que están contendiendo por la conciencia colectiva: la izquierda y la derecha, la neoliberal -tremendamente desacreditada- y la de transformación. Temas como la construcción del nuevo aeropuerto en Santa Lucía, el Tren Maya, y los programas sociales para el bienestar, se han mantenido en el centro de la discusión mediática donde una de estas narrativas se opone y cuestiona estas propuestas, buscando siempre regresar al esquema neoliberal.

Una de estas narrativas, la neoliberal, está peleando con el "fantasma anacrónico del anticomunismo", como lo sostiene Epigmenio Ibarra, quien considera inaplazable la convicción de combatir la corrupción, sobre todo aquella en la relacionada con el periodismo.

Numerosos son los escándalos de periodistas vendidos y arrodillados ante el poder, por citar alguno está el de el montaje de Carlos Loret de Mola en el caso de Florence Cassez, que, junto con otros sucesos similares, le valieron que los cibernautas lo bautizaran como "Lord Montajes".

La polarización en las redes sociales digitales nubla la crítica genuina que sale desde la opinión de izquierda, plantea Sabina Berman, pues la audiencia, es decir, los cibernautas, celebran cuando desde la izquierda surge un esbozo de crítica hacia el presidente de México, Andrés Manuel López Obrador, y en cambio, reprueban que las plumas de izquierda hablen bien de las políticas actuales y critiquen a quienes buscan regresar a las prácticas pasadas. Los twits de algunos líderes de opinión de derecha, son atacados por miles de bots o cuentas automatizadas, de forma vulgar y procaz mediante infundios e improperios.

En tiempos de incertidumbre y sozobra, generada por el virus Covid-19, diversos medios de comunicación han presentado el tema politizando la emergencia sanitaria de México, y utilizado las cifras de fallecidos como una herramienta de golpeteo al gobierno federal. Ejemplo de ello fue cuando en TV Azteca, el conductor Javier Alatorre llamó a la desobediencia del subsecretario de Salud en México, al decir al aire que "ya no le hagan caso a López Gatell.

La responsabilidad y la ética de este comunicador quedaron en entredicho, tras causar una gran polémica y debates en las redes sociales digitales por las consecuencias que pueden tener las palabras de este periodista para la salud de la población en caso de hacer caso a lo que él sugiere. Por ello las audiencias tundieron al conductor y comenzó a propagarse el término de "periodismo sicario". 
Durante la emergencia sanitaria declarada en México por la llegada al país del Coronavirus, se han esparcido rumores, desinformación y noticias falsas que en conjunto crearon una infodemia. Muestras de ello fue la noticia en varios estados y municipios, donde existía el rumor de que en los centros de salud inyectaban a los pacientes contaminados por este virus para que se murieran, o bien, que si un usuario del servicio de salud llegaba a la clínica sin el virus, ahí lo adquiría. Otra noticia falsa fue que el virus atacaba principalmente a los adultos mayores.

En no pocos casos, tales rumores eran dados por buenos por algunos medios de comunicación. Por ello es preciso cuestionar la responsabilidad de los medios de comunicación tanto tradicionales como digitales, pues la información que difunde tiene consecuencias directas en la salud de la población.

Pero los medios masivos digitales no han sido los únicos responsables de las fake news y la infodemia, sino que la red social de whats app ha jugado un papel muy importante al ser donde se propaga con gran facilidad rumores y desinformación, llegando a causar un alto costo de vidas, sin que este sea necesariamente un dato comprobable en las estadísticas de las defunciones.

\subsection{DISCUSIÓN TEÓRICA}

Harold D. Lasswell enunciaba que la escencia del periodismo es la denuncia. Escudriñar y encontrar lo que el poder quiere ocultar, y exigirle cuentas. Partiendo de esta premisa es que se analizó el actuar de algunos medios de comunicación en el contexto de pluralización de medios de comunicación, las fake news e infodemia propagada principalmente en las redes sociales virtuales.

A partir de la revolución tecnológica, la información ha pasado a ser rápida (inmediata), super abundante y es valorada como una mercancía, es decir, ya no vale por su verdad subi que está sometida a las leyes del Mercado y de la oferta y la demanda (Ramonet, 2002).

Sin embargo, una mayor información no necesariamente significa mayor libertad, pues también provoca que aumente la confusion. Para Ramonet, la sobreabundancia de información ha creado un caos y al mismo tiempo es una nueva forma de censura pues aquello que vale la pena conocer se esconde abajo de montañas de información basura, y aquí podemos agregar la información falsa o fake news.

Pese a la rapidez e inmediatez de la información que han propiciado las nuevas tecnologías, no se debe perder de vista el propósito del periodismo: dotar de información al ciudadano, para que sea libre y soberano, de esa forma el periodismo contribuye al bienestar general de una sociedad.

Kovach y Rosenstiel (2012) sostienen que el periodismo debe su lealtad a los ciudadanos, por ello debe mantener idependencia de aquellos de quienes informa. El periodismo proporciona la información necesaria para crear un panorama más amplio y profundo de los asuntos que afectan a la sociedad, de 
modo que cuente con los elementos para participar en el debate público y exigir a los gobernantes responder a las expectativas ciudadanas, que lleve a ejercer un gobierno que beneficie a las mayorías.

El periodismo, de acuerdo con Kovach y Rosenstiel (2012), tiene como principios la verdad, lealtad, verificación, independencia, foro público, significante sugerente y relevante, exhaustividad, respeto a la conciencia individual, y el control independiente del poder; tales principios constituyen la esencia del periodismo y alientan a los ciudadanos a reivindicar una información de calidad que les permita ser capaces de gobernarse a ellos mismos, de ser libres.

La infodemia que se vive actualmente en México se encuentra determinada por la relación que existe entre los medios de comunicación y el poder, que es uno de los aspectos que proponen Kovach y Rosenstiel (2012), toda vez que la línea editorial de los medios de comunicación están determinados por los dueños de los mismos.

\subsection{MÉTODO}

Esta investigación se basa en una metodología cualitativa, a través de la técnica del análisis de contenido de diferentes medios de comunicación, tanto tradicionales (televisión, radio y prensa), como medios alternativos digitales, así como de la información que circula en las redes sociales digitales propagada por usuarios con un alto número de seguidores (influencers). El análisis de contenido se centra en el tratamiento procesos sociales recientes de la escena nacional.

Al hacer el análisis de contenido en algunos medios tradicionales de comunicación como Televisa y Tv Azteca, se puede observar que estos medios anteriormente tenían una línea editorial dictada desde Los Pinos, y con el cambio de regimen politico dejaron de estar subyugados al poder. Después de que siempre informaron por consigna, se encontraron con la libertad de expresion.

\subsection{RESULTADOS}

La derecha mexicana ha utilizado diferentes coyunturas políticas y sociales para propagar noticias falsas y rumores en el mundo digital, principalmente a través de algunos medios de comunicación digitales y tradicionales que tienen presencia en el espacio virtual. Procesos sociales como el paro nacional feminista y la pandemia del virus COVID-19 fueron el terreno fértil para el virus de la desinformación.

La infodemia tiene una rápida y alta tasa de transmisión, similar al Coronavirus, que puede llegar a tener graves consecuencias en la sociedad, con implicaciones que van desde afectaciones a la salud pública, hasta la desacreditación de movimientos sociales genuinos como el femeninismo, o de gobiernos legítimos. 
El análisis de contenido de diferentes medios de comunicación, tanto tradicionales (televisión, radio y prensa), como medios alternativos digitales permitió observer que en México existen medios alternativos de comunicación que en el mundo digital se constituyen en un esfuerzo para combater la infodemia y las fake news.

Por citar algunos ejemplos de ello, Rompeviento es un medio de comunicación digital que da cabida a voces y movimientos sociales que no figuran en los medios de comunicación tradicionales. Otros medios digitales que se han ganado el prestigio y la confianza de las audiencias son Desinformémonos, Periodistas de a pie, Contralínea, SinLínea.mx, Polemón, Gurú Político, A Barlovento Informa, entre otros.

Por el contrario, los medios de comunicación tanto tradicionales como digitales que se han asumido como un contrapeso del poder, es decir, como una oposición al gobierno de la Cuarta Transformación, son numerosos, entre los que podemos citar está el Diario Reforma, Aristegui Noticias, El Heraldo de México, entre otros, a los que se agregan periodistas y columnistas que figuran en varios medios de comunicación, como Ciro Gómez Leyva y Carlos Loret de Mola, así como youtubers como Chumel Torres y Callo de hacha.

\section{CONCLUSIONES}

Para combatir las fake news y la infodemia, es necesario que los usuarios del mundo digital sigan medios de comunicación serios o formales, sin embargo hay que tener en cuenta que ello no significa que sean veraces. El prestigio de un medio no siempre corresponde con la calidad de su información.

Por otra parte, tanto medios de comunicación como sus lectores y usuarios de redes sociales digitales deben evitar propagar rumores o noticias falsas, retomando la ética, valor que entró en desuso en la era de las fake news y la infodemia.

La infodemia amerita la reflexión sobre la responsabilidad de los medios de comunicación para salvaguardar la salud de la población, pues la información falsa y la desinformación sobre temas como el virus Covid-19, pueden ocasionar muertes.

La vigilancia y regulación de la información que presentan los medios de comunicación, no debe confundirse con censura, como la oposición o la narrativa conservadora lo querrá hacer ver. La única defensa de la transformación del país es la libertad para poder debatir de forma libre.

Recientemente, en agosto de 2021, durante la conferencia de prensa "Mañanera" del presidente Andrés Manuel López Obrador, se inauguró una sección denominada “Quién es quién en las mentiras”, la cual es una respuesta a la ola de infodemia desatada durante su gobierno, mediante la cual busca desmentir la información falsa o errónea que difunden diferentes medios de comunicación y periodistas, 
los cuales se han caracterizado por recurrir a fake news para desacreditar al gobierno federal en diversos temas, muchos de los cuales tienen que ver con la gestión o el manejo de la pandemia en México.

De esa forma, la infodemia se ha combatido desde diversos medios de comunicación digitales y tradicionales que se apegan a la imparcialidad y la verdad, o que al menos publican las dos versiones de una noticia; y también se combate desde el gobierno mismo, que en su derecho de réplica, responde a los señalamientos de sus opositores.

En ese escenario, las redes sociales digitales y las nuevas plataformas tecnológicas han jugado un rol fundamental no solo para informar a la población y crear opinión pública, sino para que los usuarios puedan conocer otras versiones más verídicas sobre lo que sucede en la realidad, de forma que puedan formar su propia opinión que no sea influenciada por noticias falsas o sesgadas.

"En una época de engaño universal, decir la verdad es un acto revolucionario": George Orwell.

\section{Conflicto de intereses}

Los autores declaran no tener conflicto de intereses con respecto al presente estudio. 


\section{FUENTES CONSULTADAS}

Gamba, Malthus (2019). La conferencia mañanera: pesadilla de los conservadores. En Sinlinea.mx. Consultado en https://sinlineamx.com/la-conferencia-mananera-pesadilla-de-los-conservadores/ Kovach, Bill Kovach y Rosenstiel Tom (2012). Los elementos del periodismo. Penguin Random House Grupo Editorial España.

Ibarra, Epigmenio (2018). De la llamada "comentocracia” y sus afanes. En sin embargo.mx. Consultado en https://www.sinembargo.mx/15-12-2018/3511249

Monzón Arribas, Cándido (1987). La opinión pública. Teorías, concepto y métodos. Editores Tecnos, España.

Ramonet, Ignacio (2002). El periodismo del nuevo siglo. Los periodistas están en vías de extinción, recuperado en https://www.semana.com/vida-moderna/articulo/periodismo-del-nuevo-siglo/50591-3

Sharp, Gene (2003). De la Dictadura a la Democracia. Un Sistema Conceptual para la Liberación. 